\title{
An Overview of Sewage Treatment Rates in Chinese Cities
}

\author{
Dzivaidzo Mumbengegwi*, Tianxin Li and Jean Pierre Muhoza
}

School of Civil and Environmental Engineering, University of Science and Technology Beijing, Beijing, China

\begin{abstract}
Wastewater treatment for urban areas has become a very important factor in the improvement of environmental quality. Increasing rates of urbanisation has increased environmental stresses, emphasising the importance of environmental protection. Sewage treatment is the most effective method to improve water quality. However, a recent increase in the sewage treatment rates has not improved the overall water quality in China. Data collected from the China Statistical Yearbooks has shown that there has been an increase in sewage treatment rates, particularly in larger cities. With 3350 wastewater treatment facilities ranging from super large facilities that can cater to a population of 1 million, to small facilities that cater to smaller populations of less than 100000 . The overall water quality remained low due to the unavailability of wastewater pipelines to connect to the WWTP. Possible ways to improve the situation is to introduce water reuse systems, which requires a certain percentage of water is expected to return to the water supply. This will replenish stressed water sources as well as provide incentive to ensure wastewater is effectively transported for treatment.
\end{abstract}

Keywords: Wastewater treatment; Urbanisation; Environmental quality

\section{Introduction}

Wastewater management has been a major issue concerning environmental quality since the beginning of urbanisation. Various methods have been used to ensure sewage produced by urban populations is adequately treated to maintain suitable environmental health [1]. Urban areas consist of a collection of various activities, such as domestic, industrial, manufacturing and irrigation. The constant use of large quantities of water can put a large strain on the quality of water resources. Challenges posed by the discharge of untreated or partially treated wastewater from cities can be traced back to poor waste collection and management by local authorities. Water quality is a measurement of the condition of water relative to surrounding environment [2]. This refers to the chemical, physical and biological characteristics of water. Water quality is often used with reference to a set of previously set standards. Sewage treatment regulates the concentration of various parameters which affect the overall quality of the water. China has one of the largest populations of any country and although the country itself is relatively large in area, most of the Chinese population lives in urban areas [3]. This increase in population density increases waste production.

\section{Relevance}

Water is an important resource needed for all human activities. The transportation and treatment of sewage should be carefully monitored in order to ensure pollutants are not unnecessarily released into the environment. An indicator system can help to track progress in the collection and treatment of wastewater. Implementation of a cohesive system which monitors the same aspects for a region or country can supply information with can be used to gauge this progress. The data collected can then be used by policy makers and legislators who need a clear view of types of programmes that work well and areas that need more attention. This indicator system is purely subjective, with a wide array of information that can be used based on available information and desired outcome.

\section{Overview of Current Situation}

\section{Domestic wastewater}

China has been experiencing rising urbanisation rates, growing from $36 \%$ in 2000 to $55 \%$ in 2015 [4]. With this rise in urban population, there is also a rise in wastewater discharge. Wastewater discharge has risen from 41.5 billion tons in 2000 to 69.5 billion tons in 2013 . This represents a $65 \%$ increase over just 12 years [5]. The increasing affluence and urban densification will result in further increases in sewage production. Large cities have an average sewage treatment rate of $80 \%$; however, the national average was at $69 \%$ in 2013 . The major difference in treatment rates across the country may be due to the wastewater network connection, which was at $46.8 \%$ in 2013 [6]. According to the UN, urbanisation rates are expected to reach $60 \%$ by 2020. Domestic wastewater discharge is expected to rise in relation to population growth.

\section{Industrial wastewater}

The quantity of untreated industrial wastewater discharge has been decreasing since 2008, while GDP has experienced a faster increase [7]. This is due to two main initiatives which were put in place from the 12th Five Year Plan. The plan increased government spending on environmental protection. More stringent regulations were put in place to penalise heavy polluters [8]. Key water quality indicators monitored under the Five Year Plan were COD, NH4, Total Nitrogen, Phosphorous, Petroleum, Volatile Phenol, Lead, Mercury, Cadmium, Hexavalent Chromium, Total Chromium and Arsenic [6].

The standards vary across the country with some regions developing their own local discharge standards for water pollutants, particularly in areas such as Beijing, Guangdong and Shanghai. This would mean different areas would require different levels of sewage treatment. This could greatly affect the overall sewage treatment rate of a specific urban area. Urban areas with more stringent standards tended to have a higher

${ }^{*}$ Corresponding author: Dzivaidzo Mumbengegwi, School of Civil and Environmental Engineering, University of Science and Technology Beijing, Beijing, China, Tel: + 86-10-62333541; E-mail: dmumbengegwi@gmail.com

Received April 06, 2018; Accepted April 20, 2018; Published April 27, 2018

Citation: Mumbengegwi D, Li T, Muhoza JP (2018) An Overview of Sewage Treatment Rates in Chinese Cities. Int J Waste Resour 8: 333. doi: 10.4172/22525211.1000333

Copyright: (c) 2018 Mumbengegwi D, et al. This is an open-access article distributed under the terms of the Creative Commons Attribution License, which permits unrestricted use, distribution, and reproduction in any medium, provided the original author and source are credited. 
GDP, resulting in more municipal funding to improve sewage treatment capabilities and availability [9].

Agriculture is a major factor for nonpoint source pollution. Agricultural activities account for almost $50 \%$ of COD discharge and $32 \%$ of NH4 discharge [7]. These are pollutants being discharged into the environment without the ability to effectively treat the affected water bodies. Nonpoint pollution sources have a compounding effect on low sewage treatment rates in lower tier cities and rural areas. The uneven treatment of wastewater has led to a relatively low water quality around the country.

\section{Financial Resources}

Wastewater treatment technology was chosen based on affordability, the wastewater composition, and overall effectiveness [10]. For some areas where GDP was lower than the national average or the wastewater composition has changed over time; the result becomes that the sewage treatment facilities are not adequate. Thus reducing sewage treatment rates in that region. Increasing discharge fees may help to improve facilities, however, adequate research must be undertaken in order to ensure the appropriate wastewater technology is in use [11].

Economic viability and financial constraints may also affect treatment levels. As of 2013 (Table 1), the highest sewage treatment rate in cities was at $77.5 \%$, with 3836 treatment facilities with the total capacity of 149 million cubic meters per day. The wastewater treatment rate has been increasing over time; however, there are many connecting factors that affect the real treatment rate such as the daily operations of the treatment plants, and supporting infrastructure. In some cases, there is a high sewage treatment rate, however, the supporting infrastructure such as sewage collection systems and piping are not adequate for the transportation of all sewage produced within the urban area, thus leaving some sewage to be disposed of using unsanitary methods.

\section{Treatment and Disposal}

Medium scale treatment plants have the widest variety of treatment processes. These include biofilm, membrane bioreactor and constructed wetlands. Such processes are not suitable for larger or smaller scale

\begin{tabular}{|c|c|c|c|c|c|}
\hline Number & City & $\begin{array}{l}\text { Total investment/ } \\
\text { million RMB }\end{array}$ & Number & City & $\begin{array}{c}\text { Total } \\
\text { investment/ } \\
\text { million RMB }\end{array}$ \\
\hline 1 & Ningxia & 36.3375 & 14 & Hubei & 136.75 \\
\hline 2 & Gansu & 57.7 & 15 & Henan & 138.3375 \\
\hline 3 & Jilin & 72.9625 & 16 & Shanxi & 149.4444 \\
\hline 4 & Yunnan & 79.1875 & 17 & Anhui & 176.9125 \\
\hline 5 & Tianjin & 95.82222 & 18 & $\begin{array}{c}\text { Inner } \\
\text { Mongolia }\end{array}$ & 193.2667 \\
\hline 6 & Hunan & 107.7375 & 19 & Beijing & 193.4111 \\
\hline 7 & Jiangxi & 108.375 & 20 & Liaoning & 212.3875 \\
\hline 8 & Guangxi & 114.6 & 21 & Zhejiang & 269.8125 \\
\hline 9 & Sichuan & 114.8625 & 22 & Hebei & 272.9667 \\
\hline 10 & Heilongjiang & 118.5875 & 23 & Guangdong & 373.8625 \\
\hline 11 & Chongqing & 119.975 & 24 & Jiangsu & 448.025 \\
\hline 12 & Fujian & 125 & 25 & Shandong & 456.925 \\
\hline 13 & Shanghai & 135.675 & & & \\
\hline \multicolumn{3}{|c|}{ National Average } & \multicolumn{3}{|c|}{172.5673171} \\
\hline
\end{tabular}

Table 1: Wastewater treatment investment in Chinese urban areas, 2013. treatment plants due to the volume of wastewater to be treated on a daily basis. COD is the most commonly measured indicator during wastewater treatment. Thus the COD removal can be used to rate treatment effectiveness.

\section{Wastewater infrastructure}

The increasing importance in environmental protection can be seen in the number of WWTP built around the country. A period of rapid construction can be seen from 2009 to 2012. An increase in government spending for environmental protection was a major cause for this boom in construction, which mirrored the increase in the rate of urbanisation (Figure 1).

Sewage treatment rate was highest along the coastal cities, mostly because of the higher GDP in cities such as Shanghai, which is a financial hub. This area is a highly urbanised economic zone. Municipalities were more likely to be stringent with environmental regulations due to the area being densely populated. There was also a tendency that the population in this area desired an improved environmental quality as they were more affluent and generally wealthy. Overall, the sewage treatment rate was high with a national average of $77 \%$. The ultimate goal would be to have $100 \%$ sewage treatment rate. This becomes difficult to achieve because of the various sources and transportation of wastewater. In densely populated regions, it was economically sound to provide a centralised collection and treatment system. In sparsely populated regions, it was less economically sound to provide a centralised system, thus resulting in non-point discharge of semi or untreated wastewater. As each region's economy improves, the sewage treatment rate should also improve (Figure 2).

The urban drainage pipe load represented the average amount of sewage which was effectively transported from the source to the treatment site. This indicator had a wide spread, which showed the differences in the efficiency of pipe transportation for drainage across the country. Areas with a higher GDP had a higher pipe load index. The pipe load depends on the amount of sewage to be transported as well as the distance it is to travel to reach the sewage treatment plant. Centralised sewage treatment plans would require a larger pipe load as wastewater is collected from all sources within the city. The lower the

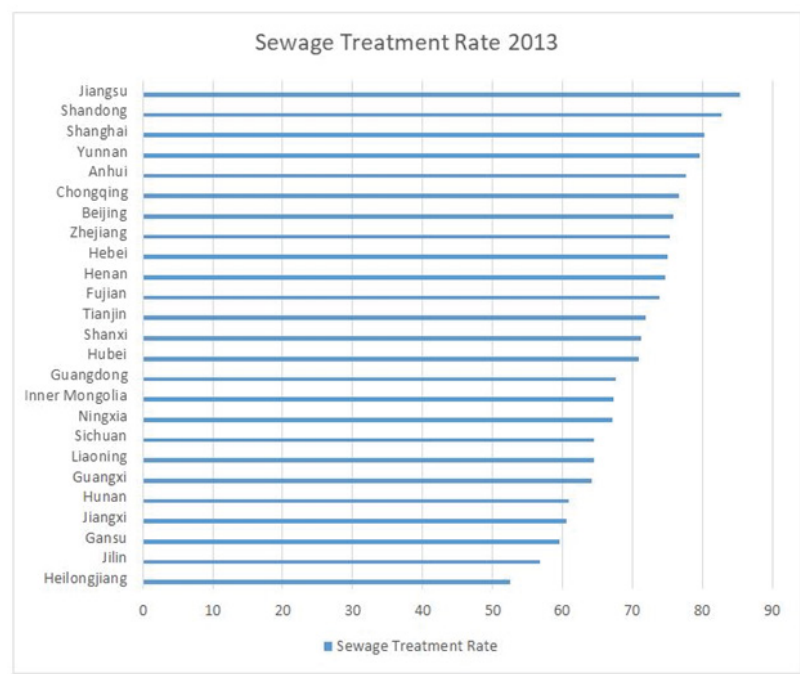

Figure 1: Sewage treatment rate in Chinese cities, 2013. 


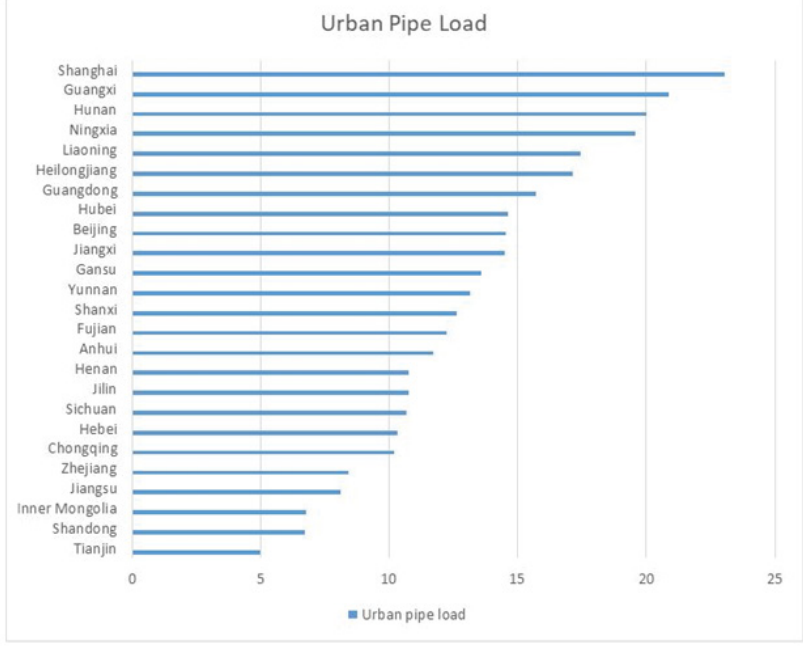

Figure 2: Urban wastewater pipe load in Chinese cities, 2013.

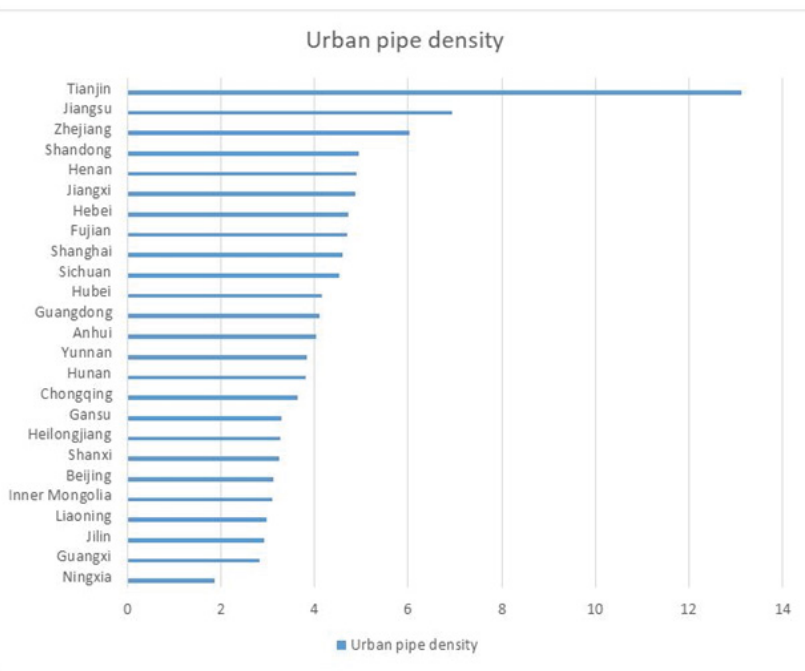

Figure 3: Urban wastewater pipe density in Chinese cities, 2013.

pipe load, the less centralised the treatment facilities (Figure 3).

Urban pipe density represented the length of wastewater drainage piping within urban areas. Tianjin had the highest with $13 \times 104 \mathrm{~km}$ length on average. This was nearly double that of the next city Jiangsu. The pipeline density works in tandem with the pipeline load. A longer network of pipeline, the more volume can be held. It should also be noted that the width of the pipeline also affects the decision of the overall density needed. The density also connects to more points in a dense urban layout (Figure 4).

\section{Treatment capacity}

Treatment rates in urban areas are analysed by scale, treatment process, geographic distribution, and discharge standards. Of the 3836 wastewater treatment plants operating in China, medium scale waste water treatment plants consisted of $75 \%$ of the total amount $[12,13]$. COD removal efficiencies for medium scale plants were at $85.5 \%$ on average. Mainstream technologies used across China are oxidation ditch (30.5\%), anaerobic/anoxic/oxic process (16.2\%) activated sludge

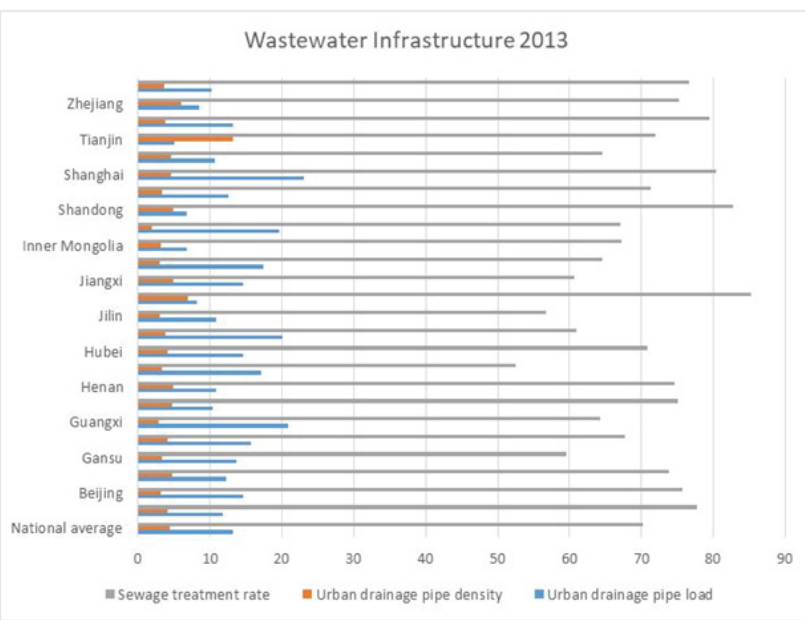

Figure 4: Urban wastewater treatment capacity in Chinese cities, 2013.

(10\%), anaerobic process $(8.2 \%)$ and sequencing batch reactor $(6.8 \%)$. Sludge treatment involved thickening, dehydration and eventual disposal in sanitary landfills. All wastewater treatment plants have online monitoring systems to ensure compliance and for effective data collection.

The Chinese government issued some policies to regulate strictly the sewage treatment industry in order to guide China's sewage treatment market. However, China's municipal sewage discharge keeps growing with the rapid urbanization and growing urban population. Daily municipal sewage discharge reached 150 million cubic meters in 2016. It is estimated that China's domestic sewage discharge will keep growing with the ever-increasing urban population. The Chinese government plans to raise the efficiency of collecting sewage by increasing sewage pipe network by 125,900 kilometres, which helps raise the capacity utilization ratio of sewage treatment plants.

The boom in WWTP construction did not necessarily mirror the requirements of each region. Some areas such as Beijing, Guangdong and Liaoning have outlined their own wastewater treatment requirements. These requirements tend to be more stringent than the national government's regulations. Due to the differences in GDP around the country, many different levels of treatment facilities were constructed. Large scale treatment plants are highly automated and require fewer people to operate the facility. This meant there was a higher electricity cost to running the plant. In smaller cities, this cost may have hindered the affordability of a large scale plant. Therefore, it is seen that small scale and medium scale plants were far more popular as this reduced electricity costs, personnel cost as well as chemical consumption. This method of choosing what type of WWTP to construct was not based on the intended sewage treatment rate. Although wastewater was being treated, as required by government regulations, it was not stipulated by how much the sewage should be treated and by what capacity.3\% of WWTP constructed were super large scale, which were built in large cities with populations of more than 10 million. Large scale WWTP accounted for $13 \%$. Medium scale WWTP were the most popular covering $75 \%$ of all treatment plants constructed, with $9 \%$ being small scale plants. The central Chinese government requires each city to have at least one WWTP. A small city in China has a population of at least 100000 residents. This increased the popularity of the medium scale treatment plant. According to the Ministry of Housing and Construction of China, about $77 \%$ of all cities have waste water treatment plants. There 
Citation: Mumbengegwi D, Li T, Muhoza JP (2018) An Overview of Sewage Treatment Rates in Chinese Cities. Int J Waste Resour 8: 333. doi: 10.4172/2252-5211.1000333

Page 4 of 4

was no emphasis on the construction of supporting infrastructure, such as sewage pipelines which transport wastewater to the treatment facility. This may have led to under reporting of sewage treatment rates. The sewage which was efficiently piped to the treatment facilities may not have been representative of the wastewater being produced within the city.

\section{Conclusion}

Water is a finite resource which is necessary for almost all human activities. Increased industrialisation and urbanisation puts stress on available water resources. Water reuse is an effective approach in solving water quality problems. Currently, environmental regulations require wastewater to be treated, but to no particular extent. In larger cities such as Beijing and Guangdong, more stringent water quality regulations have been put in place to ensure waste water is treated to the point where it can be released into water bodies for reuse and recycling. Such systematic water quality analysis can be used across the country at both local and national levels.

The sewage treatment rate was based on a number of factors. The capacity, function and number of wastewater treatment plants were important. The chosen model had to be suitable for the wastewater characteristics for the serviced area. However, the sewage treatment rate was not the only factor in the overall water quality. Urban drainage pipelines affected the transportation of wastewater from discharge points to centralised treatment facilities. This did not take into account nonpoint sources such as agriculture. The disparity between sewage treatment rates and the national environmental index for water quality show there is still a long way to go for water quality improvement in China.

This research provided information on which areas need improvement as well as provide a look at which systems are successful.
Such information can be used for future reference to decide which regions need more funding and for which part of the treatment line, be it wastewater collection, transportation or treatment.

\section{References}

1. Wang G, Lu Y (1999) Intergrated assessment of urban environment in China. J Environ Sci 11: 272-278.

2. Zhang J, Zeng W, Shi H (2016) Regional environmental effeciency in China: Analysis based on a regional slack-based measure with environmental undesirable outputs. Ecological Indicators 71: 218-228.

3. https://data.worldbank.org/products/wdi

4. Jin L, Zhang G, Tian H (2014) Current state of sewage treatment in China Water Res 66: 85-98.

5. Wu G, Miao Z, Shao S, Jiang K, Geng Y, et al. (2018) Evaluating the construction efficiencies of urban wastewater transportation and treatment capacity: Evidence from 70 megacities in China. Res Conservation Recycling 128: 373-381.

6. National Bureau of Statistics of China (2013) Ministry of Environmenta Protection of the People's Republic of China Statistical Yearbook 2008-2013.

7. www.chinawaterrisk.org

8. Chen X, Geng Y, Fujita T (2010) An overview of municipal solid waste management in China. Waste Manag 30: 716-724.

9. Pandit A, Minne E, Li F, Brown H, Jeong H (2015) Infrastructure ecology: an evolving paradigm for sustainable urban development. J Clean Prod 163: 19 27.

10. https://www.un.org/sustainabledevelopment/cities/

11. Dizdaroglu D (2015) Developing micro-level urban ecosystem indicators for sustainability assessment. Environmental Impact Assessment Review 54: 119124.

12. Sun Y, Chen Z, Wu G, Wu Q, Zhang F, et al. (2016) Characteristics of water quality of municipal wastewater treatment plant in Chins: implication for resources utilization and management. J Clean Prod 131: 1-9.

13. Wei YD, Li H, Yue W (2017) Urban land expansion and regional inequality in transitional China. Landsc Urban Plan 163: 17-31. 